\title{
“Quem sabe faz (ou já fez) ao vivo!”: Um ensaio teórico sobre a indissolubilidade entre a prática e a aprendizagem
}

\author{
"Who knows does (or already did) live!": An essay about the indissolubility \\ between practice and learning
}

\author{
Sergio Vogt ${ }^{1}$ \\ Yara Lucia Mazziotti Bulgacov ${ }^{2}$ \\ Rafael Carvalho Machado ${ }^{3}$
}

\begin{abstract}
Resumo
A aprendizagem, como tema de investigação, tem sido explorada pelas perspectivas cognitiva, experiencial e social e, mais recentemente, a partir da prática. Assim, neste ensaio teórico, em se tratando de uma reflexão sobre como ocorre o processo da aprendizagem na prática, objetiva-se desenvolver uma argumentação que revele a indissolubilidade entre a prática e a aprendizagem, propondo um conjunto metodológico na investigação empírica da aprendizagem por meio dessa abordagem teórica. Para isso, foi realizado, por meio de um resgate histórico, a contextualização sobre o cenário que favoreceu esse novo olhar sobre a prática e possibilitou o surgimento das bases teóricas que se dedicam em estudá-la. Em seguida, uma vez reconhecido o potencial dessa nova oportunidade no horizonte da pesquisa acadêmica, a prática passou a ser considerada como lócus da aprendizagem. Assim, foram apresentados argumentos que realçam a conexão direta e estreita entre a concepção de prática e de aprendizagem, visto que se estabelece uma relação mútua, equivalente e de constituição, pois a aprendizagem constitui e se constitui por meio de práticas diversas. Por fim, foi sugerido um conjunto metodológico que viabilizasse a pesquisa que envolve a aprendizagem e sua relação (indissolúvel) com a prática, especialmente quando é demandada a construção de evidências a partir de um olhar para o passado, ou seja, quando as práticas e o aprendizado fruto do envolvimento com elas já ocorreram.
\end{abstract}

Palavras-chaves: Prática. Aprendizagem. Conhecimento. Teorias da Prática. História de Vida.

\begin{abstract}
Learning as a research topic has been explored for several decades through different perspectives - cognitive, experiential and social. Recently, there was an interest in understanding learning from practice. Thus, this essay, when it comes to a reflection on how the learning process occurs in practice, aims to develop an argument that reveals the indissolubility between practice and learning and proposes a methodological set in the empirical investigation of learning by this theoretical approach. To do so, a historical inquiry was carried out to contextualize the scenario that flourished this new view on the practice and enabled the emergence of theoretical bases that are dedicated to studying it. Then, once the potential of this new opportunity on the horizon of academic research was recognized, the practice came to be considered as the locus of learning. Thus, arguments have been presented that highlight the direct and close connection between the conception of practice and learning, insofar as a mutual, equivalent and constitutive relationship is established since learning constitutes and is constituted by diverse practices. Finally, it was suggested a methodological set that enabled the research involving learning and its (indissoluble) relationship with practice, especially when it is demanded the construction of evidence from a look into the past, that is, when the practices and learning from involvement with them has already occurred.
\end{abstract}

Keywords: Practice. Learning. Knowledge. Practice Theories. Life History.

Doutorando em Administração pela Universidade Positivo - UP na linha de pesquisa de Organização e Mudança, Mestre em Administração pela Universidade Federal do Paraná - UFPR na linha de pesquisa de Estratégia e Análise Organizacional. Afiliação: Universidade Positivo. Brasil. Lattes: http://lattes.cnpq.br/2460179204334500 Orcid: http://orcid.org/0000-0001-6710-7070 Email: sergiovogt@gmail.com

2 Possui Doutorado em Educação pela UNESP-Universidade Estadual de São Paulo, Campus Marília; Mestrado em Psicologia pela PUC_SP, Pontifícia Universidade Católica de São Paulo. Afiliação: Universidade Positivo. Brasil. Lattes: http://lattes.cnpq.br/6606590329311722 Email: ybulgacov@gmail.com

3 Possui graduação em Administração Pública (EAESP-FGV, 2004), especializado em Gestão de Qualidade e Produtividade (UFPR, 2009) e em Gestão de Moda (SENAI, 2011). Afiliação: Universidade Positivo. Brasil. Lattes: http://lattes.cnpq.br/6660943880326557 


\section{Introdução}

A aprendizagem, como tema de investigação, tem sido explorada há diversas décadas por meio de diferentes perspectivas - cognitiva, experiencial e social (Godoi \& Freitas, 2008; Kolb, 1984; Lave, 1992; Wenger, 2009). Nos estudos organizacionais, dentro dessas diferentes abordagens, o tema é alvo de pesquisa, principalmente no que se refere aos aspectos da aprendizagem organizacional (Argyris \& Schön, 1978; Cook \& Yanow, 1993; Easterby-Smith \& Lyles, 2011; Fiol \& Lyles, 1985; Schön \& Argyris, 1997; Yanow, 2000).

Mais recentemente, embora existam alguns indicativos já na década de noventa, surgiu o interesse pela compreensão da aprendizagem a partir da prática. Essa lente supera a tendência individualista das correntes cognitiva e experiencial e, mesmo que também se apresente como uma visão social da aprendizagem, busca complementar alguns aspectos desse olhar, como quando centraliza como unidade de análise a prática (Bispo, 2013a, 2013b, 2015; Gherardi, 2006, 2009; Gherardi \& Strati, 2014; Lave, 2015; Lave \& Wenger, 1991; Wenger, 1998).

O interesse na utilização dessa perspectiva para estudo da aprendizagem ocorreu em virtude do movimento conhecido como o "retorno da prática" (Nicolini, 2012; Schatzki, Cetina, \& Savigny, 2001). O significado desse regresso da prática e como isso ocorreu são complementares à busca por alternativas para o estudo de fenômenos como o da aprendizagem. Assim, neste ensaio teórico, em se tratando de uma reflexão sobre como ocorre o processo da aprendizagem na prática, objetiva-se desenvolver uma argumentação que revele a indissolubilidade entre a prática e a aprendizagem, propondo um conjunto metodológico na investigação empírica da aprendizagem por meio dessa abordagem teórica.

Acredita-se que o entendimento do entrelaçamento entre a aprendizagem e a prática, e a posterior realização de pesquisas que levem isso em consideração em diferentes contextos, pode contribuir com a compreensão de processos organizacionais à medida que o fenômeno do aprendizado for considerado de forma holística, principalmente quando observado o relacionamento de agentes humanos e não humanos nesse percurso. Dessa maneira, serão também necessários recursos metodológicos que deem conta da complexidade do fenômeno que se pretende estudar.

Para isto, neste artigo é realizada, primeiramente, por meio de um resgate histórico, uma contextualização sobre o cenário que favoreceu um novo olhar sobre a prática e possibilitou o surgimento das bases teóricas que se dedicam em estudá-la. Em seguida, são apresentados argumentos que realçam a conexão direta e estreita entre a concepção de prática e de aprendizagem, com ênfase no conceito de knowing in practice (Gherardi, 2009; Gherardi \& Strati, 2014; Nicolini, Gherardi, \& Yanow, 2003; Strati, 2003). E, ao final, é sugerido um conjunto metodológico para se estudar empiricamente a aprendizagem baseada na prática.

Como ponto de partida para o atingimento dessas aspirações, parte-se em busca de esclarecimentos sobre o pano de fundo existente que culminou com o retorno da prática. Para isso, a próxima seção, ao dar ênfase ao cenário em que ocorreu esse regresso, descreve e contextualiza essa trajetória.

\section{Contextualização histórica: o cenário que favoreceu um (novo) olhar sobre a prática}

Parece que a ideia platônica de que a melhor vida seria a vida do filósofo, dedicada ao aprendizado e à contemplação da verdade (Nussbaum, 1986, p. 138) que, na esfera filosófica e, posteriormente, científica, não foi atribuída à prática o seu apropriado espaço de reflexão. E nem mesmo a iniciativa aristotélica de desconstrução parcial dessa ideia colocou a prática no seu devido lugar. Talvez porque, mais tarde, com Kant, novamente se defenderam os pressupostos do Idealismo, reforçando ainda mais que o mundo das ideias era suficiente para o entendimento da realidade (Hamlin, 2000).

Porém as reflexões sobre a 'teoria geral do conhecimento' - episteme (Furlong \& Marsh, 2010) - não se mantiveram unicamente centradas nessa base de pensamento idealista. Contrário a essa visão, surgiu o Realismo, argumentando que existe uma realidade exterior no sentido de que "as coisas são exatamente como as percebemos" (Hessen, 2000, p. 53). Isto parece ter incentivado, no período do lluminismo, que René Descartes apontasse para o método como 'a única forma de se alcançar a certeza absoluta', ou seja, a verdade. Esse mesmo período também foi marcado pelo surgimento do Empirismo, que, na relação direta com o Realismo, criticava a doutrina das ideias inatas, como apontou Locke (1973) ao considerar a 
experiência como fonte central do conhecimento. Posição também sustentada por Hume (1973) ao afirmar que o conhecimento nasce da experiência, e não por raciocínio. Essas bases de pensamento, lançadas pelos pressupostos do Realismo e do Empirismo, disponibilizaram um suporte para a construção de outras correntes epistemológicas, como o Positivismo, que surgiu nas Ciências Sociais com Augusto Comte, na terceira década do século XIX, que se ateve ao uso do raciocínio e da observação para descobrir as leis lógicas que regem o mundo (Comte, 1978).

Da mesma forma como ocorreu com o Positivismo, com perspectiva objetivista e premissas similares, surgiu o Pragmatismo. Contrário ao Intelectualismo que, segundo Hessen (2000), foi uma tentativa de mediação entre o Racionalismo de Descartes e o Empirismo de Locke e Hume, toma como critério de verdade o valor prático das coisas. Como o positivismo, critica a metafísica e baseia-se no empirismo radical ao voltar-se para o concreto (James, 1979).

Com esse 'pano de fundo', podemos entender como se deu a constituição de um conjunto de pensamentos que predominaram até meados do século XX. Nesse período, na análise organizacional, surgiram abordagens e perspectivas alternativas que se preocupavam com aspectos da subjetividade, do discurso e com a práxis nas Ciências Sociais (Vizeu, 2010, p. 39). Dessa forma, foi dada uma maior ênfase nas chamadas "ciências do espírito", conforme apontado por Viana, Pierangeli, e Brito (2016).

A consideração da subjetividade e discurso deu novo fôlego ao surgimento de novas perspectivas nos estudos organizacionais. Inaugurou-se, na segunda metade do século $\mathrm{XX}$, um período caracterizado por diferentes guinadas, entre as quais pode-se destacar: a histórica (Burke, 2005; Le Goff, 1998; Vizeu, 2010); a interpretativa (Morgan \& Smircich, 1980; Reckwitz, 2002); a linguística (Brown, 2017; Habermas, 1990; Sombra, 2008) e a da prática (Gherardi, 2006, 2012; Gherardi \& Strati, 2017; Nicolini, 2012; Ortner, 1984; Schatzki, 2002). Cada uma com suas características e, por vezes, compartilhando de pressupostos semelhantes.

A abordagem da prática, que interessa para esta reflexão, oferece uma ruptura radical com as formas de compreender as questões sociais, pois apresenta alternativas para as Ciências Sociais ao colaborar com a compreensão dos fenômenos organizacionais, conforme defende Nicolini (2012). O autor acredita, que ao estabelecer a prática enquanto unidade de análise para o estudo dos assuntos organizacionais, pode-se contribuir com a 'teoria das organizações'. Seu argumento fundamental é que a teorização organizacional se tornou demasiadamente abstrata e distanciada das atividades concretas a que se propunha descrever. Essa ruptura com pressupostos positivistas e pragmatistas leva a uma busca por uma nova lógica: a lógica da prática (Sandberg \& Tsoukas, 2011) como uma forma de resolver o problema de conhecimento gerado pelas perspectivas mais tradicionais da ciência, especialmente em organizações.

No entanto, a promoção do regresso da prática à unidade de análise e à construção de respostas, principalmente para os estudos organizacionais, não se deu da noite para o dia. O que ocorreu foi uma trajetória até que se divulgasse o "practice turn" (Schatzki et al., 2001), uma vez que também não houve a elaboração de uma única teoria da prática, mas uma série de princípios que constituíram um corpo teórico que deu sustentação e promoveu a prática a objeto de estudo.

O movimento de colocar a prática novamente como finalidade de análise apareceu, inicialmente, com Ortner (1984). A autora cita que teóricos como Karl Marx, Pierre Bourdieu (1978), Anthony Giddens e Marshall Sahlins fizeram parte da construção das bases das teorias da prática. Afirmou que, no desenvolvimento teorético de ambos, existia um olhar para o "on the ground" em referência à vida concreta (Ortner, 1984, p. 143). Reckwitz (2002), ao também realizar um resgate dos principais teóricos que construíram os fundamentos das teorias da prática, adicionou outros a essa relação, como John Dewey, Charles Taylor e Judith Butler.

Mais tarde, Nicolini (2012) cita que também fazem parte desse conjunto de teóricos que deixaram uma herança para as teorias da prática Friedrich Nietzsche, Martin Heidegger e Ludwig Wittgenstein. Na mesma intenção de apontar os fundamentos das teorias da prática, Gherardi (2006) descreve que alguns desses autores fizeram parte das raízes filosóficas do conceito de prática (Marx, Heidegger e Wittgenstein) e que outros, das raízes sociológicas (Bourdieu, Giddens e, diferente dos demais, adiciona Harold Garfinkel). Portanto, existe uma série de autores e pressupostos teóricos que dão base para a teorização a partir do olhar sobre a prática. Destaca-se, assim, que os pressupostos trazidos por tais autores, e outros até agora 
aqui não mencionados, como Foulcault ou Vygotsky e Leontiev, alicerçaram esse regresso da prática. Portanto, tendo cada um desses teóricos trazido alguma contribuição para o estudo da prática, formaramse alicerces para a elaboração de uma teorização baseada na prática. Essa grande variedade de origens culmina num conceito polissêmico de prática (Gherardi \& Strati, 2014). As abordagens acerca dos Estudos Baseados em Práticas - EBP - são diferentes, constituindo um campo ao que se convém denominar teorias da prática, no plural.

Assim, uma vez realizados esses apontamentos que contextualizam um caminho histórico caracterizado por rupturas, parte-se, agora, em direção a elucidar os fundamentos dessa corrente teórica que procurou suplantar as perspectivas dominantes e que vê a análise da prática como uma possibilidade de oferecer entendimento aprofundado e uma refinada teorização dos fenômenos organizacionais.

\section{Fundamentos das teorias da prática - Os alicerces para se olhar a prática}

A virada da prática ocorreu num momento em que, nos estudos organizacionais, o exame das organizações como "coisas" ou então apenas como 'discursos teóricos' estava migrando para o 'estudo das organizações' como um 'processo social', criando, assim, um terreno fértil para essas novas possibilidades teóricas. Especialmente por sua capacidade de fornecer uma visão processual das questões organizacionais e colocar em primeiro plano o papel central das atividades humanas, e não mais uma visão puramente pragmática ou então experiencial (Nicolini, 2012).

A visão processual das organizações deixa de entendê-las como uma substância e passa a compreendêlas como um conjunto de relações que produz e organiza o social. Nesse sentido, a ontologia plana passa explicar a realidade social sem a utilização de níveis (Schatzki, 2016), tratando de entender a relação entre as ações e arranjos materiais (Schatzki, 2012), e entre atores humanos e não-humanos (Latour, 2012), em práticas interrelacionadas que compõem um mundo de relações que não se restringe a uma realidade local (Nicolini, 2017). A mudança de visão de uma organização de "coisa" para "processo" permite entender a realidade como essa rede em constante manutenção ou transformação.

As teorias da prática são inerentemente relacionais e veem o mundo como um 'conjunto contínuo', com nexos e alianças de práticas. Nelas encontra-se uma tentativa de romper com teorias que abrigam dualidades, pois argumenta-se como vantagem que uma visão do social (baseada na prática) possibilita dissolver (e não resolver) os dualismos entre ator/sistema, social/material, corpo/mente e teoria/ação (Gherardi, 2006, 2012; Gherardi \& Strati, 2014; Nicolini, 2012).

Essa nova e diferente forma de teorização organizacional - os EBP (Gherardi, 2009; Gherardi \& Strati, 2014) - é considerada como um caminho de uma jornada orientada para a 'boa ciência social'. Tornando o investigador mais articulado e capaz de perceber as diferenças que compõem o universo complexo e multifacetado em que vivemos e que (se) reflete também o (no) contexto organizacional. Essa "boa ciência" é generativa e não eliminativista, pois proporciona uma compreensão mais rica e cheia de nuances do mundo, e não apenas respostas simplificadas. Portanto, seu objetivo é aumentar a nossa capacidade de estabelecer conexões entre os fenômenos (Nicolini, 2012, p. 215).

Visto que houve a construção de um solo fértil que favoreceu o retorno da prática, e que surgiram possibilidades para que se avançasse na sua investigação enquanto objeto de análise, passou-se a desenvolver conhecimento por meio da teorização baseada na prática (Gherardi, 2006, 2009, 2012; Gherardi \& Strati, 2014; Nicolini, 2012; Nicolini \& Monteiro, 2017).

\subsection{A teorização baseada na prática}

Uma saída necessária para o entendimento da selva polissêmica da "prática" é recorrer àqueles que se dedicam a pesquisar e defini-la, como Reckwitz (2002, p. 249), que descreveu a prática (no singular) como um termo que se refere a toda ação humana (em contraste com a teoria). E que as práticas (no plural) têm o sentido de práticas sociais, termo usado por Schatzki et al. (2001), mas também encontrado em Wenger (1998, p. 47) quando afirmou que "o conceito de prática implica fazer, mas não apenas fazer em si mesmo. 
É fazer em um contexto histórico e social que dá estrutura e significado ao que fazemos. Nesse sentido, a prática é sempre prática social".

Reckwitz também utilizou o termo em alemão, praktik, para definir a prática como um tipo de comportamento rotineiro que consiste em vários elementos interligados entre si, como "a way of cooking", e não apenas o cozinhar como uma ação humana. Dessa maneira, a prática é um "nexo disperso de fazeres (doings) e dizeres (sayings)" (Schatzki, 2012, p. 14). Essa definição foi ampliada mais tarde por Gherardi (2006, p. xi) ao afirmar que se deve incluir também o "feeling". Desse modo, a prática, ou uma prática social, envolve corpo, mente, coisas (atores não humanos segundo Gherardi (2012, p. 10)), conhecimento, discurso e linguagem, estrutura e processo (Reckwitz, 2002).

Silvia Gherardi complementa essa conceituação da prática como sendo "o terreno em que os sujeitos e os objetos tomam forma, a linguagem torna-se o discurso e o conhecimento é mobilizado e mantido" (Gherardi, 2006, p. xiii-xiv). Defende-se, assim, que o conceito de prática permite a análise das conexões sociais entre indivíduos, organizações, instituições e contextos situados, em que essas conexões se formam e os intermediários são usados para que se estabeleça essa união. Por essa razão, reitera que a visão da prática empregada à pesquisa oferece um vocabulário holístico e um framework sensibilizador para a investigação empírica nas Ciências Sociais.

Tem-se assim, um olhar ontológico da prática, a qual é multifacetada por ser composta por um conjunto de atividades que adquirem significado, as quais são reconhecidas como uma unidade (e não simplesmente como uma ação situada). Considera-se também, nessa ontologia da prática, que existe uma relação com a temporalidade, na medida em que ela precisa ser repetida a fim de ser reconhecida socialmente, pois as diferentes práticas que compõem o mundo social ocorrem no espaço e no tempo e possuem uma natureza que é, ao mesmo tempo, estática, mas fluida, visto é mutável. E, uma vez realizada, introduz um ordenamento de elementos humanos e não humanos (Gherardi, 2009; Nicolini, 2012).

Ademais, além dessas características, a prática é padronizada, senão não pode ser considerada como uma prática (Nicolini, 2012, p. 84). Isto corrobora o fato de ter que ser reconhecida socialmente. Dessa forma, a prática é, ao mesmo tempo, constituidora da, mas também composta, pela realidade social, e foi descrita por Schatzki (1991, p. 654) como uma multiplicidade de ações interligadas e regidas por estruturas inter e intrapessoais. Dessa forma, a prática passa a ser um conceito analítico que permite a interpretação de como as pessoas se engajam e participam ativamente no mundo (Gherardi, 2009, p. 357).

Esse conceito analítico permite a identificação e a caracterização de uma ou mais práticas. Além disso, pode-se afirmar que as práticas são constituídas por um conjunto de atividades, as quais são compostas por ações carregadas de significado que, por sua vez, também possuem uma característica: são formadas por operações, concebidas como a unidade básica da ação humana (Nicolini, 2012, p. 108). O reconhecimento dos elementos constituidores da prática contribui para que ela seja delimitada e se torne possível a sua observação enquanto objeto de investigação.

Tendo em vista essa elucidação conceitual, para que se realize um debate sobre a teorização baseada nesse conceito, deve-se destacar que as práticas precisam ser estudadas analiticamente, e não apenas descritivamente. Esse alerta é necessário, pois as representações, fruto de uma descrição, podem revelar algo em primeiro plano, mas ocultar outros significados. Assim, representar as práticas com a ideia de que elas podem simplesmente serem observadas e, de forma neutra, narradas, é assinar um projeto que pode vir a ser considerado como ideológico, ou então, de certa maneira, limitado (Nicolini \& Monteiro, 2017, p. 6). Isto exige uma atenção ainda maior por parte dos pesquisadores que almejam realizar estudos dessa natureza.

Por certo que as práticas precisam ser tematizadas e transformadas em 'objetos de análise', a fim de serem examinadas como alguma coisa que, de fato, existe (Gherardi, 2006, 2009, 2012; Gherardi \& Strati, 2014; Nicolini, 2012, 2016; Nicolini \& Monteiro, 2017). Uma das possibilidades que surgem para o emprego dessa perspectiva teórica é na investigação da aprendizagem, especialmente no que se refere à conexão do aprendizado com a prática (Gherardi, 2009; Gherardi \& Strati, 2014; Nicolini et al., 2003; Strati, 2003). Dessa maneira, a seção seguinte irá concentrar-se na construção e apresentação de fundamentos que justificam essa união. 


\section{A indissolubilidade entre a prática e a aprendizagem}

As práticas são consideradas o loci da aprendizagem (Gherardi, 2009), pois a aprendizagem é construída como participação na prática, visto que mente e corpo, conhecedor e conhecido, sentimentos e emoções, entendimento e conhecimento se tornam entrelaçados (Gherardi, 2006). Em síntese, argumenta-se que a prática é que conecta o "saber com o fazer" (Gherardi \& Strati, 2014, p. 6). Dessa maneira, rejeita-se a instrumentalização da explicação sobre aprendizagem e defende-se que o conhecimento "não reside na cabeça das pessoas, mas em uma atividade situada em práticas sociais" (Gherardi \& Strati, 2014, p. xviii).

Diante dessa postura, surge o conceito de "knowing in practice" (KinP). Perspectiva que vai ao encontro do que Lyles e Easterby-Smith (2003) identificaram como lacuna a ser preenchida nas pesquisas acadêmicas sobre aprendizagem dentro dos estudos organizacionais, uma vez que reconheceram que era (e ainda é) necessário entender sobre aprendizagem, "mas que faltava pesquisa sobre o "real" e "verdadeiro" aprendizado e conhecimento" (p. 645 - aspas adicionadas do original). O KinP se fundamenta na sociologia organizacional e em uma ontologia construtivista, e não vê o conhecimento como objeto, mas o percebe como um processo social, humano, material, estético, bem como emocional, firmado em práticas em que "fazer (doing) e o conhecer (knowing) são um e o mesmo" (Gherardi, 2006, p. xii). A partir dessa perspectiva, o saber e o fazer estão conectados como remete o bordão de um apresentador televisivo: "Quem sabe faz ao vivo!".

Nesse sentido, não existe separação entre conhecimento e aprendizado, pois ocorrem simultaneamente no decorrer da ação. Portanto, dentro dessa visão, o conhecimento passa a ser visto não como uma substância, objetivado em um livro ou materializado em outro objeto, nem meramente uma propriedade posse de um indivíduo. O conhecimento é mobilizado no desempenho de práticas, as quais envolvem aspectos humanos e não humanos (Gherardi \& Strati, 2014). Assim, a aprendizagem se torna "um curso de ação, materialmente mediada, situada dentro de práticas" (Gherardi, 2006, p. xiv). Essa visão expõe determinados indicativos epistêmicos, pois se percebe na prática, por meio de atividades concretas, a produção e o uso do conhecimento, uma vez que o conhecimento tornou-se visível, observável e descritível, sem a necessidade de se inferir sobre o que está na cabeça das pessoas.

Essa perspectiva da aprendizagem (e também do conhecimento) sugere uma 'natureza fluída' do conhecer, que é ancorado em práticas, as quais conectam o individual com a sociedade (coletivo), pois "cada prática individual é (está) situada dentro de um campo de outras práticas que se ramificam em todas as direções" (Gherardi, 2006, p. vvii - parênteses adicionados do original). Em virtude disso, no exemplo usado pela autora, o simples fato de escovar os dentes, mesmo em se tratando de uma prática individual, relaciona-se com outras práticas e outras atividades, como a compra da escova em um supermercado ou as orientações dadas pelos profissionais da Odontologia sobre como proceder nessa tarefa. Vê-se que no knowing in practice também se identifica a mediação de aspectos não humanos, como artefatos e tecnologias que se envolvem no processo.

Assim, à medida que ocorre a interligação entre diferentes práticas, tem-se a formação de uma rede de práticas que é denominada de 'textura de práticas' (Gherardi \& Strati, 1990). E mesmo que em uma prática exista uma forma, não necessariamente homogênea, e em um conjunto de diferentes práticas entrelaçadas haja continuidade, nessas práticas e nesses agrupamentos, não tão circunscritos, que irá ocorrer a aprendizagem (Gherardi, 2006). Nessa dinâmica, a aprendizagem não é vista apenas como um processo cognitivo individual, pois a prática antecede a cognição, nem é encarada como fruto de uma experiência concreta, já que vai além do que considera a visão da aprendizagem experiencial, de forma que a aprendizagem é percebida como algo que ocorre mediada pelo social, levando-se em conta que é constituída (e se constitui) por práticas diversas.

Dessa forma, tem-se também o estabelecimento da conexão entre o conhecimento e a prática em virtude da relação mútua e equivalente entre praticar (practising) e conhecer (knowing). Convém, portanto, ressaltar que, dentro desse processo, atenta-se mais para os aspectos do conhecimento tácito (Polanyi, 1966) do que para questões puramente objetivas que possam explicar como o aprendizado ocorre, como é o caso da argumentação sobre a aquisição e a retenção de conhecimento encontrado nas correntes cognitivista e experiencial. 
Desde a década de 90, especialmente ancorados nos trabalhos de Jean Lave e Etienne Wenger (Lave, 1992; Wenger, 1998), existe o movimento de considerar a aprendizagem encorada em práticas utilizando o conceito de comunidades de prática (Antonello \& Godoy, 2010; Ipiranga et al, 2005). Mais recentemente, o conceito de KinP tem despertado o interesse em pesquisadores para a compreensão de fenômenos organizacionais (Pimentel \& Nogueira, 2018), como da aprendizagem (Ferrazza \& Antonello, 2017). Assim, dentro dessa perspectiva da teoria da prática sobre o knowing in practice, os passos já trilhados permitem uma fundamentação que dá suporte para o argumento da relação direta e estreita entre a aprendizagem, o conhecimento e a prática. A questão não esclarecida e que permanece é: quando e como se aprende? Por isso, a fim de expor a busca por elucidar essa indagação, avança-se para a próxima seção.

\subsection{Aprender na ou com a prática? A resposta é aprendendo ao tornar-se um praticante}

Aprender não se trata somente de estudar uma cartilha proposta ou experienciar um fazer qualquer (no sentido de ação), mas de praticar (Gherardi, 2006). Na visão do knowing in practice, argumenta-se em prol da exigência de que o aprender está no 'tornar-se um praticante' (Gherardi, 2006; Gherardi \& Strati, 2014). Isto pode envolver seguir uma orientação. Porém, dentro da argumentação do 'conhecendo na prática', o aprendizado em si estaria além disso, pois seria firmado em algo mais amplo e concreto: nas práticas sociais.

Diante disso, a questão que surge é: como o indivíduo aprende praticando? Sabe-se, primeiramente, que o conhecimento agora está na prática, e não somente no que o sujeito sabe sobre ela. Assim sendo, Gherardi (2006) defende que o conhecimento não deixa de ser acessado pelo praticante por meio de formas linguísticas (por exemplo, storytelling), mas é obtido, principalmente, por outras modalidades de relacionamento na participação (ou realização) da prática. Dentro dessas diferentes formas, o aprendiz/praticante tem acesso (ou deve-se ater) ao que a autora chama de indicadores do conhecimento, que contribuem com o aprendizado ao direcionarem a atenção do interessado em aprender para objetos específicos do conhecimento.

Nesse sentido, mais do que simplesmente fazer e, por consequência, adquirir/reter conhecimento, como defendem algumas perspectivas, o indivíduo precisa envolver-se na prática, e isto inclui, por exemplo, ver e olhar. Esses termos recebem uma atenção especial de Gherardi quando destaca que a dinâmica da aprendizagem precisa de verbos sempre no gerúndio, no caso o 'seeing' (que envolve um processo automático não reflexivo) e o 'looking' (que envolve intencionalidade) (Gherardi, 2006, p. 77). Ambos são realizações que compõem o watching (observar/prestar atenção a/assistir). Além disso, a autora enfatiza o ouvir e o (buscar compreender) como formas de orientar-se por esses indicadores do conhecimento.

No mesmo sentido, Björn (2012) critica abordagens que tratam de desemaranhar o conhecimento da ação. Para a autora, ainda que um praticante tenha a sua disposição toda a informação para o desempenho de uma tarefa, nem sempre é possível identificar quais informações são relevantes, dentro de um determinado contexto social, tecnológico e econômico, para resolver situações não identificadas. Nessa perspectiva, o conhecimento não poderia ser desacoplado da atividade prática, nem pode ser entendido como uma matéria adquirida - tal como uma série de definições de dicionário. Dessa maneira, o conhecimento individual não é obtido com a apropriação de informações, mas sim como um uso competente da experiência que resulta das repetidas oportunidades de resolução de problemas e testes de soluções (Tsoukas, 2005).

Em síntese, dado o que foi apresentado até então, percebe-se que, para que haja aprendizado, tem que haver 'o praticar', missão incumbida ao praticante que "só" aprende na medida em que se envolve e ele(a) mesmo realiza a tarefa. No exercício de sua incumbência, tais tarefas irão orientar sua caminhada em direção ao atingimento dos seus objetivos e, consequentemente, na construção de aprendizagens. No desenrolar da sua postura como praticante, o indivíduo, além de agir, também irá falar sobre a prática e, durante a prática em que estiver envolvido, irá ouvir, ver e sentir. A aprendizagem, nessa perspectiva, é indissolúvel da prática, pois se constitui nela.

Diante desses argumentos e da possibilidade de utilização desse corpo teórico para a realização de pesquisas empíricas, questiona-se: como é possível o estudo da aprendizagem e qual arcabouço metodológico poderia ser usado quando se trata de um estudo baseado na prática? A seção a seguir buscar elucidar alguns aspectos que podem colaborar com a definição de uma proposta teórico-metodológica que viabilize a pesquisa que envolve a aprendizagem e sua relação (indissolúvel) com a prática. 


\section{O estudo da aprendizagem por meio de um arcabouço teórico-metodológico das práticas}

Autores que se dedicam a apresentar formas de se conduzir os estudos baseados na prática orientam como é possível a realização de pesquisas que envolvem a aprendizagem dentro dessa perspectiva. Eles argumentam que a saída é o emprego de uma epistemologia relacional (Gherardi, 2006, 2009, 2012; Gherardi \& Strati, 2014; Nicolini, 2012; Nicolini \& Monteiro, 2017), principalmente quando se argumenta que é fundamental que o conhecimento seja visto e analisado como uma atividade cooperativa (Gherardi, 2012, p. 25), ao invés de ser visto apenas como um objeto.

Diante dessa sugestão, sugere-se uma mudança, a fim de que o conhecimento passe a ser visto como um recurso para a ação e, portanto, o 'trabalhar' (work): é o uso de um conjunto de conhecimentos, e o 'trabalhando' (working), nesse sentido, irá produzir mais conhecimentos (Gherardi, 2012, p. 20). Portanto, dentro dessa nova perspectiva de se observar a aprendizagem ancorada na prática, não se busca mais estimar ou aferir a aprendizagem em um nível quantitativo, procura-se analisar o processo em que a produção de conhecimento gerou aprendizado.

Essa perspectiva baseia-se na visão do conhecimento como algo prático (practical knowledge), permitindo que sejam atribuídas algumas características para sua descrição (o que traz contribuições metodológicas para a pesquisa), entre as quais: a instância pragmática, pois é direcionada para o fazer (doing); uma temporalidade específica, uma vez que surge de uma situação e de uma ação situada; está ancorado na materialidade, dado que utiliza fragmentos de conhecimento que deriva de objetos e tecnologia; também se firma em práticas discursivas, destacando a mobilização do discurso na concretização da ação e a existência de uma sustentação histórico-cultural, visto que o conhecimento prático envolve o que aconteceu no passado, em determinado contexto, e resultou em aprendizado, ou seja, considera-se também o aspecto experiencial (Gherardi, 2012).

No que se refere à aspectos relacionados à operacionalização de investigações, usando os EBP, primeiramente, Gherardi (2012) destaca a possibilidade da realização de uma pesquisa da prática "a partir de fora" - focada na investigação da regularidade, de padrões de organização de atividades, ou "a partir de dentro", em que o ponto de vista é dos praticantes da atividade em questão. Nesse sentido, se 'a partir de fora' a atenção é no fazer (doing), pode-se inferir que 'a partir de dentro' a centralidade está no knowing. 0 destaque dessas diferentes possibilidades, não excludentes entre si, proporciona um avanço na orientação de como conduzir estudos baseados na prática, em virtude de que ambas direcionam o foco da observação do pesquisador.

Davide Nicolini também se destaca na proposição de aspectos metodológicos operacionalizantes para os estudos baseados na prática. $O$ autor lançou bases para sua proposta quando enfatizou o conceito de zoom in e zoom out para o estudo das práticas (Nicolini, 2010). E, mais recentemente, apresentando o que ele chamou de uma abordagem da prática (Nicolini, 2012). Abordagem formada por um "kit de ferramentas" com base em uma pluralidade de conceitos sensibilizadores, pertencentes a ontologias, epistemologias e metodologias distintas, mas que apresentam semelhanças entre si, formando um 'eclestismo programático' disponível aos EBP.

Esse pacote de 'conceitos sensibilizadores' também sugere um foco empírico em diferentes elementos, tais como: nos dizeres (sayings) e nos fazeres (doings), na ordem interacional, no tempo e no espaço. Propõe, ainda, que se considerem aspectos como a coreografia corporal, as ferramentas e os artefatos, assim como os aspectos mediadores do trabalho, os interesses práticos, as tensões entre criatividade e normatividade, e os processos de legitimação e de padronização. Para cada um desses atributos, como elementos que devem ser observados nos estudos baseados na prática, o autor exemplifica, por meio de questões, que estes possuem a finalidade de sensibilizar o pesquisador para a possibilidade de construção de um caminho em direção ao entendimento do fenômeno - ou seja, da(s) prática(s) observada(s) (Nicolini, 2012, p. 220).

Outra lição metodológica existente nos EPB refere-se à sugestão dada por Nicolini e Monteiro (2017) de que, em vez de procurar as razões do comportamento (organizacional ou social) dentro das pessoas, a abordagem da prática objetiva impelir o pesquisador a olhar para as relações, para 'como' os sistemas de 
ações são atados conjuntamente e o que isso implica em termos de agência, significado e empowerment. E, por que não, também aprendizagem? Nesse sentido, tem-se uma orientação de como empregar as bases teóricas que sustentam as teorias da prática de forma empírica.

Porém, com base no que foi até então apresentado, mesmo que já se tenha avançado em direção à elaboração de uma base para os estudos baseados na prática, provavelmente essa tarefa ainda não está encerrada, especialmente no que se refere aos aspectos operacionalizantes para a condução de pesquisas endereçadas à aprendizagem. Assim, se a busca é por uma "receita" que instrua o pesquisador no caminho a ser trilhado, existem alguns sinais já revelados, mas isto ainda está inacabado, principalmente quando a busca por entendimento de processos de aprendizagem não permite a observação da prática ocorrendo em um determinado momento, mas requer resgate histórico.

Portanto, mesmo sabendo-se que, metodologicamente, para conduzir e operacionalizar estudos baseados na prática existem sugestões de procedimentos metodológicos para se estudar empiricamente a aprendizagem. Questiona-se sobre a potencialidade do auxílio de metodologias tradicionais que envolvem a instrumentalização da coleta de dados em investigações dessa natureza, especialmente quando é demandada a construção de evidências a partir de um olhar para o passado, ou seja, quando as práticas foram realizadas e o aprendizado ocorreu.

Nesse sentido, tendo em vista que este artigo também se propõe a apresentar um conjunto metodológico para se estudar empiricamente a aprendizagem baseada prática, a seção a seguir traz a construção dessa proposta.

\subsection{Uma proposta de operacionalização de estudos sobre a aprendizagem na prática}

Considerando que é preciso "uma metodologia apropriada para a observação do conhecer na prática", conforme afirmaram Gherardi e Strati (2014, p. 4), e ainda dado que "o conhecimento é concebido como uma atividade mundana, situado nas práticas de trabalho" (p. 4), defende-se aqui que, em se tratando de procedimento de coleta de dados que viabilizem a investigação sobre a aprendizagem com resgate histórico, a seleção da história de vida - HV, aliada à entrevista temática, em um momento posterior ao relato da trajetória vivida, permite realizar a investigação da prática dentro da perspectiva apresentada por Gherardi, a "partir de fora", mas também o fará a "partir de dentro", ou seja, do ponto de vista dos praticantes envolvidos em determinadas práticas, como indivíduos que desempenharam certas atividades e as relatam agora ao investigador social.

Essa possibilidade decorre do fato de que, em se tratando dos estudos organizacionais, o reconhecimento da relevância da HV tem fomentado discussões na academia em virtude de sua natureza, que é, ao mesmo tempo, tática e funcional (Cappelle, Borges, \& Miranda, 2010; Closs \& Antonello, 2008; Gaffuri \& Ichikawa, 2016; Itelvino, Costa, Gohn, \& Ramacciotti, 2015; Jaime, Godoy, \& Antonello, 2007; Mageste \& Lopes, 2007; Oliveira, Correa, \& Delboni, 2017; Perazzo \& Bassi, 2007). Vista como uma estratégia qualitativa que colabora com a organização da coleta de dados, a HV permite que, ao contar sua história de vida, o narrador relate sobre o que aconteceu consigo e tornar "o implícito explícito, o escondido visto, o sem forma com forma e o confuso claro" (Atkinson, 2002, p. 125), permitindo ao pesquisador acesso a um mundo até então desconhecido para ele, ainda que possam haver limitações, como falhas na própria memória do narrador.

Na narração de uma história de vida, o narrador externaliza por meio da linguagem e de sua perspectiva pessoal as experiências vividas e os sentimentos sentidos. Estes podem suscitar aspectos de conhecimento, autoimagem e estima, assim como alegrias e satisfações. Podem, também, revelar aspectos em comum (ou discrepantes) mais do que se imagina. Enfim, por meio de histórias narradas, devido essa estratégia metodológica ser contextualizada e pessoal, afirma-se que "os outros irão nos conhecer e entender melhor" (Atkinson, 2002, p. 128). Segundo Olesen (2011, p. 144), "o fato de se produzir um texto que se apoie fortemente no engajamento e nas experiências próprias do narrador, de forma aproximada dos acontecimentos e experiências" permitirá ao investigador social acesso a conhecimentos que poderão construir uma compreensão mais clara do fenômeno que se investiga. 
Porém, escolher a história de vida como estratégia/método de pesquisa significa deparar-se com a distinção entre duas formas de história de vida que precisam ser apresentadas e são melhores retratadas com os termos na língua inglesa - life history e life stories. A primeira se refere a um relato da vida e, a segunda, são esses relatos em forma de histórias, as quais contam sobre experiências pessoais que ocorrem em um determinado contexto social e histórico, ou seja, a minha 'life history' contempla diversas 'stories of my life' (Ferrazza \& Antonello, 2017). Isto aponta para a oportunidade do uso do método da 'história temática' como forma de investigação sobre as histórias "menores" ou mais específicas que compõem a vida do narrador e que podem ser alvo do investigador social quando deseja descobrir algo em particular. Inclusive sobre processos de aprendizagem firmadas em determinadas práticas.

O método da história de vida tem a ver com uma trajetória que é maior, podendo ser da infância, passando por diferentes fases da vida até o momento atual, e pode ser usado em conjunto com outros métodos, como apontou Musson (2004). Uma dessas possibilidades é a realização da entrevista temática que, segundo Alberti (2005, p. 37), é aquela que versa sobre a "participação do entrevistado no tema escolhido". Essa autora enfatiza que a própria entrevista de história de vida "contém, em seu interior, diversas entrevistas temáticas" (p. 37). Assim, a escolha de uma em detrimento da outra deve se pautar no objetivo que se deseja atingir e, no caso da entrevista temática, seu emprego é adequado a aspectos bem definidos que se deseja conhecer. Por isso, sugere-se que ambas sejam empregadas em tom de complementariedade, a fim de descortinar processos de aprendizagem envolvendo resgates históricos em que não é possível acompanhar uma prática no momento em que é realizada.

Assim, têm-se que o emprego da narrativa, efeito de uma história de vida ou temática, permite que o pesquisador torne "visível e audível" as práticas e as atividades, os processos, as características culturais e estruturais do cotidiano do nosso mundo social, como apontou Susan Chase no Handbook de pesquisa qualitativa de Denzin e Lincon (2005, p. 664). E que isto possibilita a construção de conhecimento sobre o processo de aprendizagem a partir dessas narrativas.

Reconhecemos que essa não é a única possibilidade metodológica para revelar, por dentro, uma lógica de ação dos indivíduos. Outras abordagens culturais têm também o potencial de investigar a aprendizagem na prática: a etnometodologia, por exemplo, é um caminho importante para o estudo da aprendizagem em organizações e sofre, contudo, críticas por sua falta de estruturação (Bispo \& Godoy, 2012). A etnografia é outro caminho reconhecido, porém não se podem ignorar as dificuldades do método, sobretudo de acesso ao campo (ver Alcadipani, 2014). Defendemos a HV como uma ferramenta disponível ao pesquisador qualitativo de organizações.

\section{Considerações finais}

Dentro dos estudos organizacionais, desde que surgiram os primeiros debates de temas relacionados ao comportamento organizacional, a temática da aprendizagem se mostrou relevante em virtude de sua capacidade de fornecer um entendimento sobre diferentes processos organizacionais. Isto permitiu que esse fenômeno fosse explorado por meio de diferentes perspectivas - cognitiva, experiencial e a social.

Nesse mesmo período, ocorreu o aparecimento de uma série de correntes teóricas, que geraram fundamentos que tornavam a prática como objeto de estudo para a compreensão de diferentes fenômenos sociais. Essas diferentes lentes teóricas procuraram suplantar as perspectivas dominantes e viam na análise da prática social uma possibilidade de oferecer um entendimento aprofundado e uma refinada teorização dos fenômenos organizacionais. Assim, os pressupostos dessas perspectivas teóricas criaram uma base que sustentou o retorno da prática e a estabeleceu como uma nova possibilidade de teorização organizacional.

Por isso, neste artigo foi realizada, por meio de um resgate histórico, a contextualização sobre o cenário que favoreceu esse novo olhar sobre a prática e possibilitou o surgimento das bases teóricas que se dedicam em estudá-la. Em seguida, uma vez reconhecido o potencial dessa nova oportunidade no horizonte da pesquisa acadêmica, a prática passou a ser considerada como lócus da aprendizagem. Assim, foram apresentados argumentos que realçam a conexão direta e estreita entre a concepção de prática e de aprendizagem, uma relação mútua, equivalente e de constituição, pois a aprendizagem constitui e se 
constitui por meio de práticas diversas - o que reforça a ideia de indissolubilidade entre esses elementos. Por fim, foi sugerido um conjunto metodológico que viabilizasse a pesquisa que envolve a aprendizagem e sua relação (indissolúvel) com a prática, especialmente quando é demandada a construção de evidências a partir de um olhar para o passado, ou seja, quando as práticas foram realizadas e o aprendizado fruto do envolvimento com elas já ocorreu.

Dentro dessa perspectiva de se observar a aprendizagem ancorada na prática, procura-se analisar o processo em que a produção de conhecimento gerou aprendizado. Por isso, sugere-se que sejam utilizados os pressupostos aqui apresentados para a realização de futuras pesquisas de natureza empírica, em diferentes contextos, a fim de revelar distintos processos de aprendizagem. Para isso, acredita-se que a narrativa, fruto de uma ou mais histórias, pode ser utilizada como ferramenta na busca desse objetivo.

Portanto, se knowing é practising, então, praticar é aprender. Tem-se, assim, que a aprendizagem origina-se de um conjunto de práticas em que o sujeito praticante se envolveu no decorrer da sua trajetória de vida. Cabe ao pesquisador, interessado em descortinar processos de aprendizado, procurar nesse universo a construção de respostas para suas questões de pesquisa.

\section{Referências}

Alberti, V. (2005). Manual de história oral (3a ed.). Rio de Janeiro: Editora FGV.

Alcadipani, R. (2014). Confissões Etnográficas: Fracassos no Acesso a Organizações no Brasil. Revista Brasileira de Estudos Organizacionais, 1(1), 1-25.

Antonello, C. S., \& Godoy, A. S. (2010). A Encruzilhada da Aprendizagem Organizacional: uma Visão Multiparadigmática. Revista de Administração Contemporânea, 14(2), 310-332.

Argyris, C., \& Schön, D. (1978). Organizational learning: a theory of action perspective: Addison-Wesley.

Atkinson, R. (2002). The Life Story Interview. In J. F. Gubrium \& J. A. Holstein (Eds.), Handbook of Interview Research: Context and Method (pp. 121-141). London: Sage.

Bispo, M. D. S., \& Godoy, A. S. (2012). A Etnometodologia enquanto Caminho Teórico-metodológico para Investigação da Aprendizagem nas Organizações. Revista de Administração Contemporânea, 16(5), 684-704.

Bispo, M. d. S. (2013a). Aprendizagem organizacional baseada no conceito de prática: contribuições de Silvia Gherardi. Revista de Administracao Mackenzie, 14(6), 132-161.

Bispo, M. d. S. (2013b). Estudos Baseados em Prática: Conceitos, História e Perspectivas. Revista Interdisciplinar de Gestão Social, 2(1), 13-33.

Bispo, M. d. S. (2015). Methodological Reflections on Practice-Based Research in Organization Studies. BAR - Brazilian Administration Review, 12(3), 309-323.

Bjorn, P. (2012). How people act in sociomaterial practices. Scandinavian Journal of Information Systems, 24(2), 97-104.

Bourdieu, P. (1978). Outline of a Theory of Practice (R. Nice, Trans.). Cambridge: Cambridge University Press.

Brown, P. (2017). Narrative: An ontology, epistemology and methodology for pro-environmental psychology research. Energy Research \& Social Science, 31, 215-222.

Burke, P. (2005). Theorists and Historians. In P. Burke (Ed.), History and Social Theory (pp. 1-20). New York: Cornell University Press.

Cappelle, M. C. A., Borges, C. L. P., \& Miranda, A. R. A. (2010). Um Exemplo do Uso da História Oral como Técnica Complementar de Pesquisa em Administração. Paper presented at the VI Encontro de Estudos Organizacionais da Anpad - EnEO, Florianopólis.

Closs, L., \& Antonello, C. S. (2008). O Uso do Método de História de Vida Para Compreensão dos Processos 
de Aprendizagem Gerencial. Paper presented at the XXXII EnANPAD, Rio de Janeiro.

Comte, A. (1978). Curso de filosofia positiva. São Paulo: Abril Cultural.

Cook, S. D. N., \& Yanow, D. (1993). Culture and Organizational Learning. Journal of management inquiry, 2(4), 373-390.

Denzin, N. K., \& Lincon, Y. S. (2005). The SAGE Handbook of Qualitative Research. Thousand Oaks: Sage Publications.

Durkheim, É. (1978). As regras do método sociológico. São Paulo: Abril Cultural.

Easterby-Smith, M., \& Lyles, M. A. (2011). Handbook of organizational learning and knowledge management (M. Easterby-Smith \& M. A. Lyles Eds. Second ed.). Chichester: John Wiley \& Sons.

Ferrazza, D. S., \& Antonello, C. S. (2017). O Método de História de Vida: Contribuições para a Compreensão de Processos de Aprendizagem nas Organizações. Gestão. Org, 15(1), 22-36.

Fiol, M., \& Lyles, M. A. (1985). Organizational Learning. Academy of Management Review, 10(4), 803-813.

Furlong, P., \& Marsh, D. (2010). A skin not a sweater: ontology and epistemology in political science. In D. Marsh \& G. Stoker (Eds.), Theory and methods in political science (3. ed ed., pp. 184-211): Pallgrave McMillan.

Gaffuri, E. L., \& Ichikawa, E. Y. (2016). Num Novo País: a História de Vida de João, Imigrante e Negro e sua Territorialização pela Visão de seu Cotidiano. Paper presented at the XL Encontro Nacional da Anpad - EnANPAD, Costa do Sauípe.

Gherardi, S. (2006). Organizational Knowledge: The Texture of Workplace Learning. Oxford: BlackWell Publishing.

Gherardi, S. (2009). Knowing and learning in practice-based studies: an introduction. The Learning Organization, 16(5), 352-359.

Gherardi, S. (2012). How to conduct a practice-based study: Problems and methods. Cheltenham: Edward Elgar Publishing.

Gherardi, S., \& Strati, A. (1990). The 'texture' of organizing in an italian university department. Journal of management studies, 27(6), 605-618.

Gherardi, S., \& Strati, A. (2014). Administração e aprendizagem na prática. Rio de Janeiro: Elsevier.

Gherardi, S., \& Strati, A. (2017). Luigi Pareyson's Estetica: Teoria della formatività and its implication for Organization Studies. The Academy of Management Review, 42(4), 745-755.

Godoi, C. K., \& Freitas, S. F. (2008). A Aprendizagem Organizacional sob a perspectiva Sócio-Cognitiva: Contribuições de Lewin, Bandura e Giddens. Revista de Negócios, 13(4), 40-55.

Habermas, J. (1990). Pensamento pós-metafísico: estudos filosóficos (2. ed ed.). Rio de Janeiro: Tempo Brasileiro.

Hamlin, C. L. (2000). Realismo crítico: um programa de pesquisa para as ciências sociais. Dados [online], 43(2).

Hessen, J. (2000). Teoria do Conhecimento. São Paulo: Martin Fontes.

Hume, D. (1973). Investigações sobre o entendimento humano. São Paulo: Abril Cultural.

Ipiranga, A. S. R., Menezes, R. B. d., Matos, J. L. L., \& Maia, G. L. L. (2005). Aprendizagem como ato de participação: a história de uma comunidade de prática. Cadernos EBAPE.BR, 3(4), 01-17.

Itelvino, L. d. S., Costa, P. R. d., Gohn, M. d. G. M., \& Ramacciotti, C. (2015). Processo de Formação do Empreendedor Social: Um Estudo a partir de Narrativas de História de Vida. Paper presented at the XXXIX Encontro Nacional da Anpad - EnANPAD, Belo Horizonte.

Jaime, P., Godoy, A. S., \& Antonello, C. S. (2007). História de Vida: Origens, Debates Contemporâneos e Possibilidades no Campo da Administração. Paper presented at the I Encontro de Ensino e Pesquisa 
em Administração e Contabilidade - EnEPQ, Recife.

James, W. (1979). Ensaios em empirismo radical. São Paulo: Abril Cultural.

Kolb, D. A. (1984). Experiential learning: experience as the source of learning and development: Prentice Hall.

Latour, B. (2012). Reagregando o Social: uma introdução à teoria do Ator-Rede. Salvador: EDUFBA.

Lave, J. (1992). Learning as participation in communities of practice. Paper presented at the Annual Meeting of the American Educational Research Association, San Francisco, CA.

Lave, J. (2015). Aprendizagem como/na prática. Horizontes Antropológicos, 21(44), 37-47.

Lave, J., \& Wenger, E. (1991). Situated learning: Legitimate peripheral participation. Cambridge: University Press.

Le Goff, J. (1998). A história nova. São Paulo: Martins Fontes.

Locke, J. (1973). Ensaio acerca do entendimento humano. São Paulo: Abril Cultural.

Lyles, M. A., \& Easterby-Smith, M. (2003). Organizational Learning And Knowledge Management: Agendas For Future Research. In M. Easterby-Smith \& M. A. Lyles (Eds.), The Blackwell Handbook of Organizational Learning and Knowledge Management. New Jersey: Wiley-Blackwell.

Mageste, G. d. S., \& Lopes, F. T. (2007). O Uso da História de Vida nos Estudos Organizacionais. Paper presented at the I Encontro de Ensino e Pesquisa em Administração e Contabilidade - EnEPQ, Recife.

Morgan, G., \& Smircich, L. (1980). The case for qualitative research. Academy of Management Review, 5(4), 491-500.

Musson, G. (2004). Life Histories. In C. Cassell \& G. Symon (Eds.), Essential guide to qualitative methods in organizational research (pp. 34-44). London: SAGE Publications.

Nicolini, D. (2010). Zooming in and out: Studying practices by switching theoretical lenses and trailing connections. Organization Studies, 30(2), 1391-1418.

Nicolini, D. (2012). Practice theory, work, and organization: An introduction (1. ed ed.). Oxford: University Press.

Nicolini, D. (2016). Is small the only beautiful? Making sense of 'large phenomena' from a practicebased perspective. In A. Hui, T. Schatzki, \& E. Shove (Eds.), The Nexus of Practices: Connections, constellations and practitioners. London: Routledge.

Nicolini, D., Gherardi, S., \& Yanow, D. (2003). Knowing in organizations: A practice-based approach. New York: M. E. Sharpe.

Nicolini, D., \& Monteiro, P. (2017). The practice approach: for a praxelogy of organizational and management studies. In A. Langley \& H. Tsoukas (Eds.), The SAGE handbook of process organization studies (1 ed. ed.). London: Sage Publications.

Nicolini, D. (2017). Is small the only beautiful? Making sense of "large phenomena" from a practoce-based perspective. In The Nexus of Practices - Connections, constellations, practitioners (pp. 98-113).

Nussbaum, M. C. (1986). The fragility of goodness: luck and ethics in Greek tragedy and philosophy. Cambridge Cambridge University Press.

Olesen, H. S. (2011). Exploração do sujeito problemático: história de vida, subjetividade, experiência de vida. Educação, 34(2), 137-146.

Oliveira, E. d. J., Correa, D. A., \& Delboni, C. (2017). Meu nome é Ozires, Ozires Silva: a história de vida e de carreira de um empreendedor na perspectiva da teoria desenvolvimentista de Donald Super. Paper presented at the EnGPR, Curitiba.

Ortner, S. B. (1984). Theory in Anthropology Since the Sixties. Comparative Studies in Society and History, 26(1), 126-166. 
Perazzo, P. F., \&Bassi, C. S. (2007). Possibilidades do Método de História Oral nos Estudos em Administração. Paper presented at the I Encontro de Ensino e Pesquisa em Administração e Contabilidade - EnEPQ, Recife.

Pimentel, R., \& Nogueira, E. E. d. S. (2018). Estudos Baseados na Prática: Possibilidades Metodológicas para Pesquisas em Estudos Organizacionais. Revista Organizações \& Sociedade, 25(86), 350-370.

Polanyi, M. (1966). The Tacit Dimension. New York: Doubleday \& Company.

Reckwitz, A. (2002). Toward a Theory of Social Practices: a development in culturalist theorizing. European Journal of Social Theory, 5(2), 243-263.

Sandberg, J., \& Tsoukas, H. (2011). Grasping the logic of practice: Theorizing through practical rationality. Academy of Management Review, 36(2), 338-360.

Schatzki, T. R. (1991). Spatial Ontology and Explanation. Annals of the Association of American Geographers, 81(4), 650-670.

Schatzki, T. R. (2002). Site of the social: A philosophical account of the constitution of social life and change. University Park, PA: Pennsylvania State University Press.

Schatzki, T. R. (2012). A Primer on Practices: Theory and research. In J. Higgs, R. Barnett, S. Billett, M. Hutchings, \& F. Trede (Eds.), Practice-Based Education: Perspectives and Strategies. New York: Springer.

Schatzki, T. R. (2016). Practice theory as flat ontology. Praxistheorie. Ein Forschungsprogramm, Bielefeld: Transcript.

Schatzki, T. R., Cetina, K. K., \& Savigny, E. V. (2001). The Practice Turn in Contemporary Theory London: Routledge.

Schön, D. A., \& Argyris, C. (1997). Organizational learning: a theory of action perspective. Revista Española de Investigaciones Sociológicas, 77, 345-350.

Sombra, L. L. (2008). Gadamer e Habermas: os atritos da linguagem. Intuitio, 1(2), 171-187.

Strati, A. (2003). Knowing in practice: aesthetic understanding and tacit knowledge. In D. Nicolini, S. Gherardi, \& D. Yanow (Eds.), Knowing in Organizations (pp. 53-75). New York: M.E. Sharpe.

Tsoukas, H. (2005). The Practice of Theory: A Knowledge-based View of the Development in Organization Studies. In Complex Knowledge: Studies in Organizational Epistemology (p. 427). Oxford: Oxford University Press.

Viana, M. F., Pierangeli, A. C., \& Brito, M. J. d. (2016). A hermenêutica crítica e estudos em marketing: aproximações e possibilidades. Organizações \& Sociedade, 23(76), 92-109.

Vizeu, F. F. (2010). Potencialidades da análise histórica nos estudos organizacionais brasileiros. Revista de Administração de Empresas, 50(1), 37-47.

Wenger, E. (1998). Communities of practice: Learning, meaning, and identity. Cambridge: University Press.

Wenger, E. (2009). A social theory of learning. In D. C. Phillips \& J. F. Soltis (Eds.), Perspectives on Learning (pp. 209-218). New York: Teachers College Press.

Yanow, D. (2000). Seeing Organizational Learning: A 'Cultural’ View. Organization, 7(2), 247-268.

Submetido em: 20/07/2018

Aprovado em: 02/09/2019 